\title{
EFFECT OF BERBERINE ON OXIDATIVE STRESS CAUSED BY EIMERIA TENELLA IN CHICKEN
}

\author{
Q. ZHU, J. SUN ${ }^{1}$, M. PENG ${ }^{1}$, P. SHI ${ }^{2}$, Y. SONG \\ Y. QIAO AND Z. HUANG* \\ Key Lab of Science and Technology of Eco-textile, Ministry of Education \\ College of Chemistry, Chemical Engineering and Biotechnology \\ Donghua University, 2999 Renmin Road, Shanghai 201 620, China
}

\begin{abstract}
After coccidia infect chickens, the cecum of chickens produces oxidative stress, which is aggravated by the propagation of coccidia. The disruption of the balance of oxidant/antioxidant system causes chickens to suffer from diseases. Berberine has been shown to prevent cecum epithelial barrier damage from coccidia by suppressing the reproduction of coccidia and restore the normal functions of chicks' cecum. In the current study, effect of berberine (BBR) on the oxidative damage caused by coccidiosis was investigated. Forty-eight three-week-old chicks treated in different ways. All livers, serum and caeca were collected and the degree of oxidative stress and antioxidant enzyme activity were evaluated. The results showed that the increase in contents of free radicals in serum and cecum caused by Eimeria tenella were eliminated after daily treatment with berberine. Furthermore, level of lipid peroxidation was decreased, and superoxide dismutase activities were increased in the experimental groups treated by berberine compared to the infected birds. RT-PCR assay showed that mRNA level of superoxide dismutase was not affected by berberine. Taken together, berberine alleviates oxidative stress by increasing the activity of antioxidant enzymes such as superoxide dismutase. However, it is independent of mRNA expression of superoxide dismutase.
\end{abstract}

Key words: Antioxidant, Berberine, Chicken, Coccidiosis, Oxidative stress

Coccidiosis is a common parasitic disease caused by several species of Eimeria protozoa. Among the nine identified subspecies, Eimeria tenella is considered to be one of the most pathogenic (Guo et al., 2013). E. tenella is parasitic on the cecum, invading the intestinal cecum epithelium and destroying the integrity of intestinal mucosa

*Corresponding Authors

${ }^{1}$ Qinghai Key Laboratory of Qinghai-Tibet Plateau Biological Resources, Northwest Institute of Plateau Biology, the Chinese Academy of Sciences, Xiguan Avenue 59, Xining, Qinghai Province 810001, China ${ }^{2}$ State Key Laboratory of Bioreactor Engineering, East China University of Science and Technology, 130 Meilong Road, Shanghai 200237, China 
(Vervelde et al., 1993; Iacob and Duma, 2009). Infected chickens show typical clinical symptoms on day 4-5 post-infection, such as reduced weight gain, ruffled feathers and bloody diarrhea (Long et al., 1976; Fang et al., 2016). In severe cases, coccidiosis kills chicks.

Under normal physiological conditions, reactive oxygen species (ROS) produced by metabolism are maintained at low concentration (Masood et al., 2013). Infecting coccidia destroy the antioxidant defense system composed of superoxide dismutase (SOD), glutathione peroxidase (GPx), catalase (CAT) and other enzymes, weakens the ability of removing ROS, and leads to ROS accumulation in the body. Excessive ROS acts on unsaturated fatty acids, generating toxic lipid peroxidation such as malondialdehyde, resulting in cell swelling and pathological damage to the body (Radi and Matkovics, 1988). These symptoms are attributed to oxidative damage caused by coccidia.

Most anticoccidial drugs, such as monensin and amprolium, inhibit the normal growth, metabolism and reproduction of coccidia. However, the widespread use of these drugs has led to the emergence of drug resistance and residues in poultry (Chapman, 1997; Tajick and Shohreh, 2006), and it's urgent to find new drugs with less drug residues and low drug resistance. Herbal plants and their byproducts have many advantages, such as few drug residues and side effects, less drug resistance and low prices. They are considered to have good anti-coccidial prospects (Abbas et al., 2006). Berberine (BBR), a traditional
Chinese medicine, has also been proved to resist coccidiosis and protect the intestine of chicks (Fang et al., 2016). In this study, effect of BBR on the oxidative damage induced by coccidia was investigated to clarify its protective mechanism against coccidia in chickens.

\section{MATERIALS AND METHODS}

Materials and animal treatments: Berberine chloride (reagent grade, $>90 \%$ pure), amprolium and vitamin C (VC) were obtained from Bio Basic Inc (Shanghai, China). Fortyeight three-week-old chicks were purchased from Shanghai Pacific poultry breeders. They were divided randomly into six equal groups with four replicates per group (Table 1). Group 0 was used as a negative control indicating the uninfected without drug treatment. Group $1 \sim 2$ were, used as positive controls, infected with low/high dosage of E. tenella oocysts $\left(5 \times 10^{4}\right.$ or $5 \times 10^{5}$ oocysts each chick) without drug treatment (Bahadoran et al., 2014). Group 3 5 were infected with high dosage of E. tenella oocysts $\left(5 \times 10^{5}\right.$ oocysts each chick) and respectively treated with berberine (300 mg/kg/day), amprolium (as a drug adding control, $120 \mathrm{mg} / \mathrm{kg} /$ day $)$ and $\mathrm{VC}(500 \mathrm{mg} / \mathrm{kg} /$ day). Chicks were weighed every day and treated with berberine, amprolium or $\mathrm{VC}$ according to their weight. To avoid contamination, chickens of these groups were housed in six separate rooms. All of them had free access to water and feed and constant light was provided throughout experiment. All animal procedures in these experiments were approved by the Ethics Committee of the University of Donghua, Shanghai, China. 
Table 1. Grouping and drug treatments

\begin{tabular}{cll}
\hline Group & Dosage of $\boldsymbol{E}$. tenella oocysts & Treatments \\
\hline 0 & 0 & No \\
1 & $5 \times 10^{4}$ (low-dosage) & No \\
2 & $5 \times 10^{5}$ (high-dosage) & No \\
3 & $5 \times 10^{5}$ (high-dosage) & Berberine $(300 \mathrm{mg} / \mathrm{kg} / \mathrm{day})$ \\
4 & $5 \times 10^{5}$ (high-dosage) & Amprolium $(120 \mathrm{mg} / \mathrm{kg} / \mathrm{day})$ \\
5 & $5 \times 10^{5}$ (high-dosage) & Vitamin C $(500 \mathrm{mg} / \mathrm{kg} /$ day $)$ \\
\hline
\end{tabular}

Weight gain and survival rate: Body weights were recorded before infection and on day 8 post-infection. The numbers of alive chickens were recorded on day 8 post-infection. Relative weight gain rate and mortality of each group were calculated as follows:

Rate of relative weight gain $(\%)=$ average weight gain of each group / average weight gain of group $0 \times 100 ;$ Survival rate $(\%)=$ the number of alive chickens / total number of chickens $\times 100$.

Oocysts production counts: Excreted oocysts were counted at day 5 post-infection according to previously described methods (Long et al., 1976; Haug et al., 2006) and referred to as oocytes per gram (OPG) in faeces.

Lesion score: At day 8 of post-infection, each chicken was euthanized by ether inhalation and cervical dislocation. Livers, serum and caeca were collected. Lesion scores were evaluated according to Johnson and Reid (Johnson and Reid, 1970). A score of 0 means no lesions, 1 means slight lesions, 2 means moderate lesions, 3 means severe lesions and 4 means very severe lesions or death owing to coccidiosis.

Anticoccidial index: Anticoccidial index (ACI), as an indicator of drug efficacy, was calculated as follows (Fei et al., 2013): ACI = (Survival rate + rate of relative weight gain) (oocyst value + lesion score). Oocyst values were calculated as follows: (OPG output of each group/OPG output of group 2) $\times 100$. An ACI $<120$ indicated inefficacy, from 120 to 159 indicated limited effect, from 160 to 179 indicated moderate effect and $>180$ indicated excellent effect (Mcmanus et al., 1968).

Superoxide assay: The production of superoxide was detected according to the procedure previously described (Wang et al., 2006; Wang et al., 2010). Rubbed liver tissue or plasma samples were homogenized in $1 \mathrm{~mL}$ of $50 \mathrm{mM}$ (pH 7.8) phosphate buffer followed by centrifugation at $10,000 \mathrm{~g}$ for $10 \mathrm{~min}$. The supernatant $(0.5 \mathrm{~mL})$ was then collected and added $1 \mathrm{~mL}$ of $1 \mathrm{mM}$ hydroxylamine hydrochloride. After $1 \mathrm{~h}$ reaction at $25^{\circ} \mathrm{C}$, the mixture was added $1 \mathrm{~mL}$ of $1 \%$ $\alpha$-naphthylamide and $1 \mathrm{~mL}$ of $17 \mathrm{mM} \mathrm{p}$-aminophenylsulfonic acid. After reaction for $30 \mathrm{~min}$, n-butanol $(3 \mathrm{~mL})$ was added into the above reaction mixture, and centrifuged at $6,000 \mathrm{~g}$ for $10 \mathrm{~min}$. The specific absorption was measured at $530 \mathrm{~nm}$. The content of superoxide was calculated with sodium nitrite as standard solution. 
Lipid peroxidation evaluation: Since methane dicarboxylic aldehyde (MDA) is the endproduct of lipid peroxidation, the production of MDA was measured to evaluate lipid peroxidation. Cells were centrifuged and collected. After washing, the wet weight of cell pellets was measured. Then, $2 \mathrm{~mL}$ of TBATCA reagent $[0.25 \mathrm{M} \mathrm{HCl}$, TBA $0.375 \%$ $(\mathrm{w} / \mathrm{v})$, trichloroacetic acid $15 \%(\mathrm{w} / \mathrm{v})]$ was added to each pellet and the mixture was incubated in a boiling water bath for $30 \mathrm{~min}$. After cooling, the suspension was centrifuged at $8,000 \mathrm{~g}$ for $10 \mathrm{~min}$ and the supernatant was separated. Then, the absorbance was measured at $450 \mathrm{~nm}, 532 \mathrm{~nm}$ and $600 \mathrm{~nm}$. The concentration of MDA was calculated as follows (Dhindsa et al., 1981):

$\operatorname{MDA}(\mu \mathrm{mol} / \mathrm{g})=\left[6.452 \times\left(\mathrm{A}_{532}-\mathrm{A}_{600}\right)-0.559\right.$ $\left.\times \mathrm{A}_{450}\right] /$ pellet weight.

Superoxide dismutase (SOD) activity: SOD activity was assessed according to Babitha and Prakash (2002). The reaction mixture included $50 \mathrm{mM}$ phosphate buffer ( $\mathrm{pH} 7.8), 1.3 \mathrm{mM}$ methionine, $63 \mathrm{mM}$ nitroblue tetrazolium (NBT), $1.3 \mu \mathrm{M}$ riboflavin and plasma samples or liver tissue protein extracts. After exposure to a cool white fluorescent light with an intensity of 4,000 lux for $15 \mathrm{~min}$, the absorbance of the mixture was measured at $560 \mathrm{~nm}$. The reaction mixture without enzyme was taken as an internal control. From the resultant diagram, the volume of enzyme extract corresponding to $50 \%$ inhibition of the reaction was read and regarded as an enzyme unit.

RT-PCR: The caeca samples (approximately $0.5 \mathrm{~g}$ ) were cleaned and shredded. Then Total RNA was isolated using TRIzol reagent (TaKaRa, Tokyo, Japan). After extraction, the purified RNA was reverse-transcribed to cDNA using Reverse Transcription kit (TaKaRa, Tokyo, Japan). The cDNA and $2 \times$ Hieff $^{\mathrm{TM}}$ PCR Master Mix (YEASEN, Shanghai, China) were used for RT-PCR. RT-PCR was performed to evaluate changes of two key antioxidant genes (SOD1 and SOD2) expression. The primer sequences were shown in Table 2 . Amplification and detection were carried out using equivalent amounts of the same cDNA samples used for PCR. Levels of individual transcripts were normalized by those of $\beta$-actin analyzed by PCR. Each RT-PCR experiment was conducted in triplicate.

Statistical analysis: The data were expressed as the mean \pm stan dard deviation. Statistical

Table 2. Oligonucleotides used in this work

\begin{tabular}{lll}
\hline Primer & \multicolumn{1}{c}{ Sequence (5'-3') } & \multicolumn{1}{c}{ Description } \\
\hline SOD1_F & TTGGAGACAACACAAATGGG & SOD1 mRNA forward primer \\
SOD1_R & AGGTACAACGGTTAGCACTT & SOD1 mRNA reverse primer \\
SOD2_F & ATCAGTTGGTGTTCAAGGAT & SOD2 mRNA forward primer \\
SOD2_R & ATTCACTTGTATGCCACAGA & SOD2 mRNA reverse primer \\
ACTB_F & CTCTTCCAGCCATCTTTCTT & ACTB mRNA forward primer \\
ACTB_R & GATTCATCGTACTCCTGCTT & ACTB mRNA reverse primer \\
\hline
\end{tabular}


analysis was performed using the Student's t-test. A P-value less than 0.05 was considered as statistically significant.

\section{RESULTS}

Anticoccidial effect of berberine: The chemical structure of berberine was presented in Fig. 1. The effect of berberine on bloody diarrhoea, survival rate, OPG and lesion score were tested and observed, and ACI was calculated (Table 3). From the data, the severity of bloody diarrhoea and cecum lesions were positively correlated with dosage of E. tenella oocysts. The treatment with berberine was similar to the drug adding control and significantly alleviated these symptoms. The survival rate of group treated with berberine (group 3) was higher than that of positive controls (group 1-2). Berberine obviously reduced the amount of OPG to $4.21 \times 10^{6}$ oocytes per gram. Similar as amprolium, berberine exhibited excellent efficacy against $E$. tenella.

Table 3. The effect of berberine on chickens' performance ${ }^{*}$

\begin{tabular}{lccccc}
\hline Treatments & $\begin{array}{c}\text { Bloody } \\
\text { diarrhoea }^{\#}\end{array}$ & $\begin{array}{c}\text { Survival } \\
\text { rate }(\boldsymbol{\%})\end{array}$ & $\begin{array}{c}\text { OPG } \\
\left(* \mathbf{1 0}^{\mathbf{6}}\right)\end{array}$ & $\begin{array}{c}\text { Lesion } \\
\text { score }\end{array}$ & ACI \\
\hline Uninfected + No treatment & - & 100 & 0 & 0 & 200 \\
Low dosage infected + No treatment & ++ & $67 \pm 3.1$ & $10.1 \pm 0.6$ & $1.8 \pm 0.3$ & 101.8 \\
High dosage infected + No treatment & +++ & $50 \pm 5.7$ & $14.2 \pm 1.7$ & $3.1 \pm 0.3$ & 68.0 \\
High dosage infected + BBR & + & $83 \pm 2.3$ & $4.2 \pm 0.5$ & $1.1 \pm 0.2$ & 153.1 \\
High dosage infected + Amprolium & - & 100 & $0.1 \pm 0.03$ & $0.6 \pm 0.1$ & 195.6 \\
\hline
\end{tabular}

*Data are presented as mean or mean \pm S.D.

\#Bloody diarrhoea (- - +++ represents no, few, many and large amounts of blood)

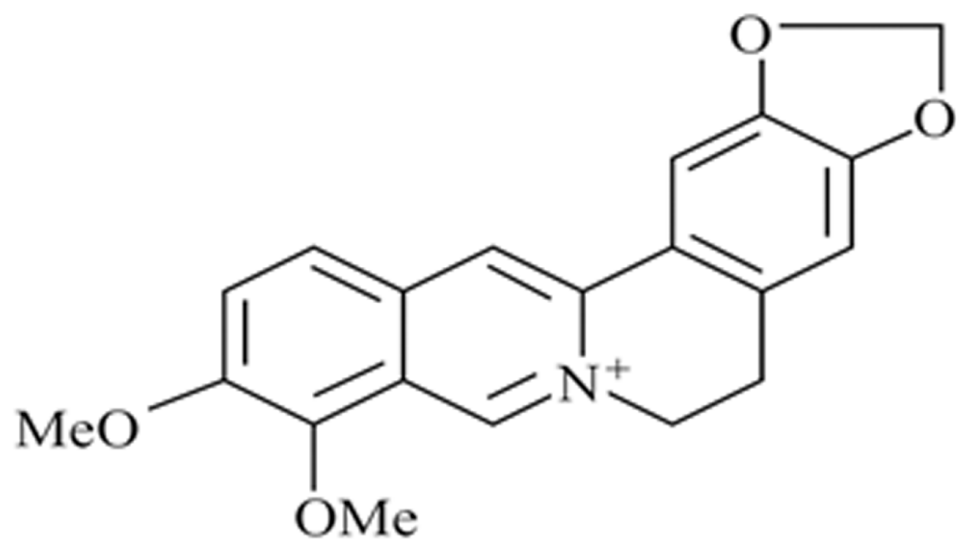

Fig. 1. Chemical structure of berberine (BBR) 


\section{Berberine reduces coccidiosis-induced} oxidative stress: Changes in superoxide contents were shown in Fig. 2. Superoxide was significantly increased in the serum, liver and cecum in the chickens exposed to high dosage of E. tenella oocysts (group 2), compared to the control group (group 0). Both berberine and amprolium effectively reduced the production of superoxide. Ascorbic acid (VC), is a physiologically multifunctional compound required for various processes in animals (Han et al., 2018) and an antioxidant that protects tissues from ROS (Harrison et al., 2012; Liu et al., 2017). As seen in Fig. $2 \mathrm{~B}$ and $2 \mathrm{C}, \mathrm{VC}$ effectively reduced excess superoxide induced by coccidiosis in the liver and cecum. Compared with the positive control (group 2), there were no significant

(A)

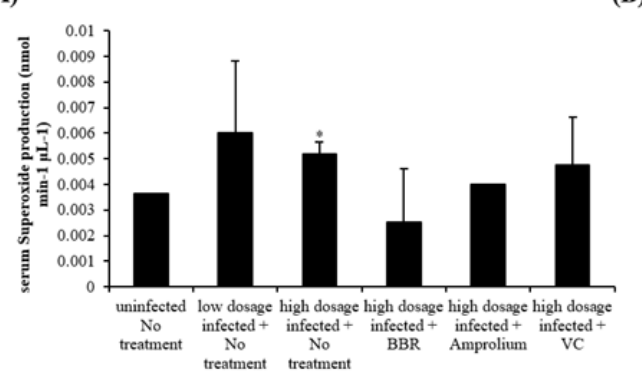

(B) changes of superoxide radical levels in serum of group 3-5. The above data indicated that the treatment of berberine helped eliminate ROS produced by coccidiosis in tissues, rather than in the blood.

Effect of berberine on lipid peroxidation induced by $E$. tenella in chickens: Excessive ROS can induce lipid peroxidation and cause membrane dysfunction and damage of membrane bound enzymes, further producing reactive oxygen species. MDA, one of the main products of lipid peroxidation, is a marker of radical-induced damage (Halliwell and Chirico, 1993). Contents of liver and cecum MDA were significantly increased in chickens infected by E.tenella, while berberine obviously inhibited their increase.

(C)
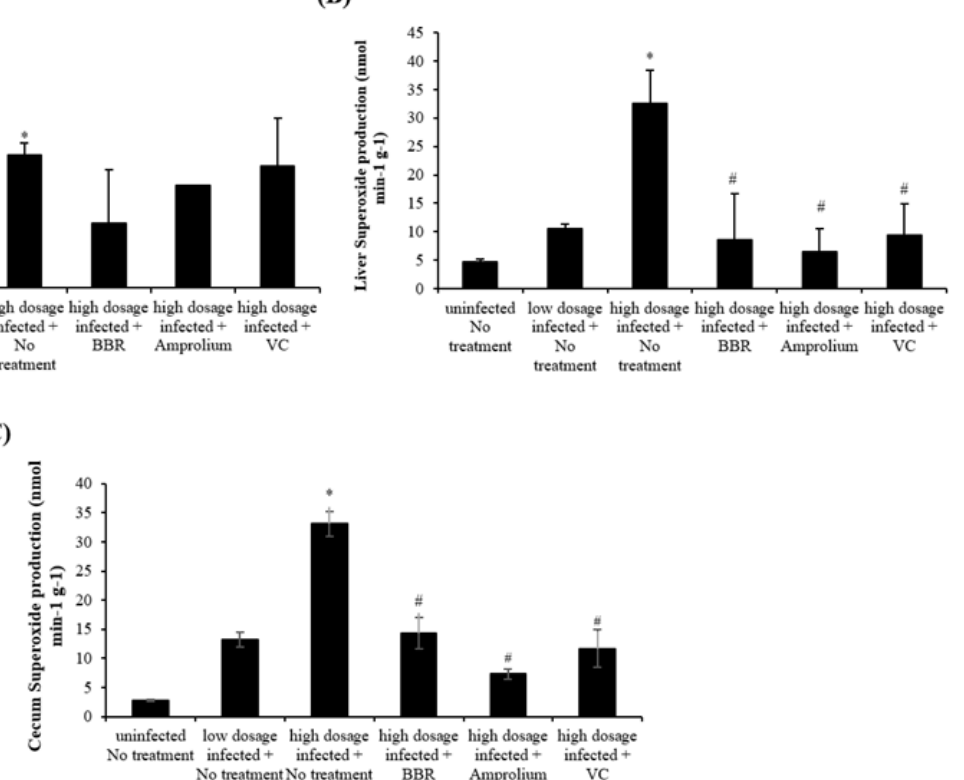

[Asterisks $(*)$ indicate statistically significant differences between positive controls (group 1-2) and negative control (group 0) $(\mathrm{P}<0.05)$. Hash marks $(\#)$ indicate statistically significant differences between infected/ treated groups (group 3-5) and positive control (group 2) $(P<0.05)$. Error bars represent mean \pm S.D.]

Fig. 2. Effect of berberine on superoxide radical levels in serum (A), liver (B) and cecum (C) of chickens 
(A)

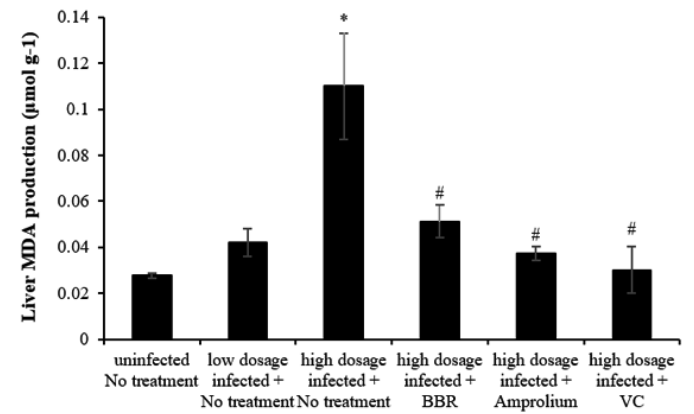

(B)

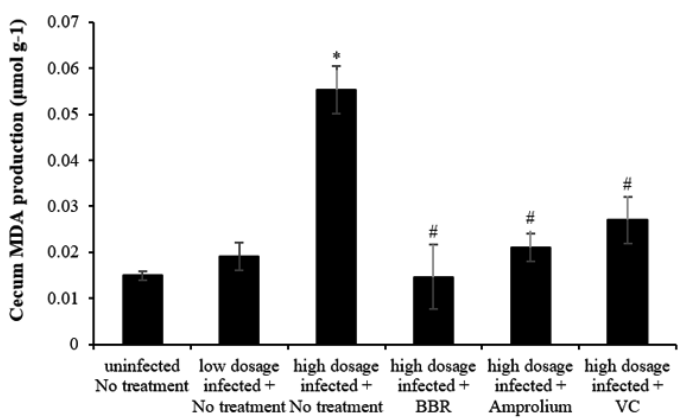

[Asterisks $(*)$ indicate statistically significant differences between positive controls (group 1-2) and the negative control (group 0) $(\mathrm{P}<0.05)$. Hash marks (\#) indicate statistically significant differences between infected/ treated groups (group 3-5) and positive control (group 2) $(\mathrm{P}<0.05)$. Error bars represent mean \pm S.D.]

Fig. 3. Effect of berberine on MDA contents in liver (A) and cecum (B) of chickens

Effect of berberine on SOD activity in chickens: In order to determine how berberine could inhibit the oxidative stress caused by E.tenella in chickens, the activity of SOD, a prominent antioxidant enzyme, was analyzed. As seen in Fig. 4, the SOD activities of positive control (group 2) were remarkably lower than those of negative control (group 0) in the serum and liver. The activities of SOD were significantly returned to normal level after treated by berberine. SOD activities also had a remarkable increase in the liver of chickens treated by ammoniaporin or VC.
Effect of berberine on mRNA levels of SOD: In animals, SOD has two isozymes, $\mathrm{Cu} / \mathrm{Zn}$ SOD (SOD1) in cytoplasm and Mn SOD (SOD2) in mitochondria respectively. Their function is to remove $\mathrm{O}^{2-}$ produced by the metabolism to prevent oxidation. Effect of berberine on expression of SOD1 and SOD2 was verified by RT-PCR (Fig. 5). Both mRNA levels of SOD1 and $S O D 2$ were increased in high-dosage infected chickens compared to uninfected chickens. However, mRNA levels of SOD showed no significant increase in those infected chickens after treated by berberine,
(A)

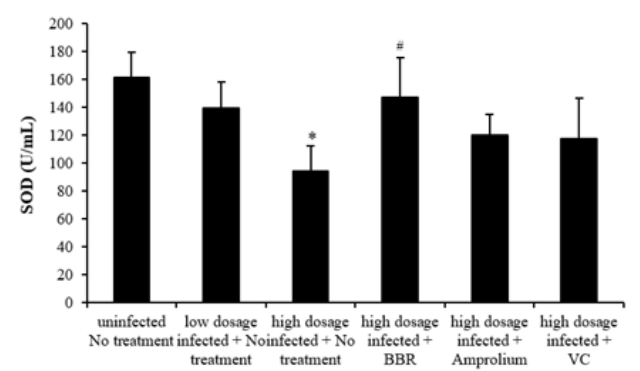

(B)

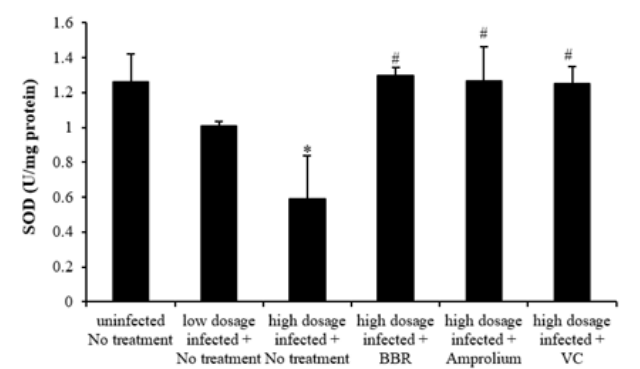

[Asterisks (*) indicate statistically significant differences between positive controls (group 1-2) and the negative control (group 1) $(\mathrm{P}<0.05)$. Hash marks (\#) indicate statistically significant differences between infected/ treated groups (group 3-5) and positive control (group 2) $(P<0.05)$. Error bars represent mean \pm S.D.]

Fig. 4. Effect of berberine on SOD activities in serum (A) and liver (B) of chickens 
(A)

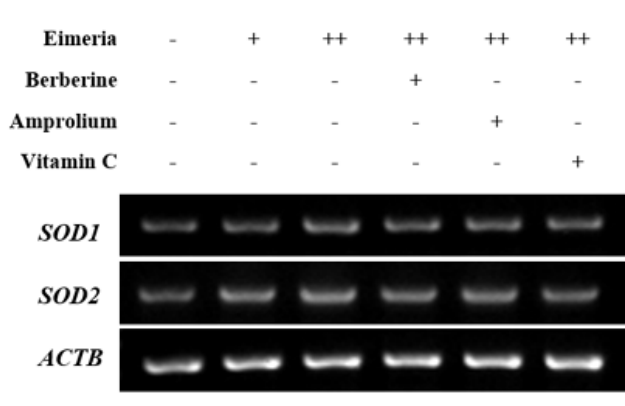

(B)

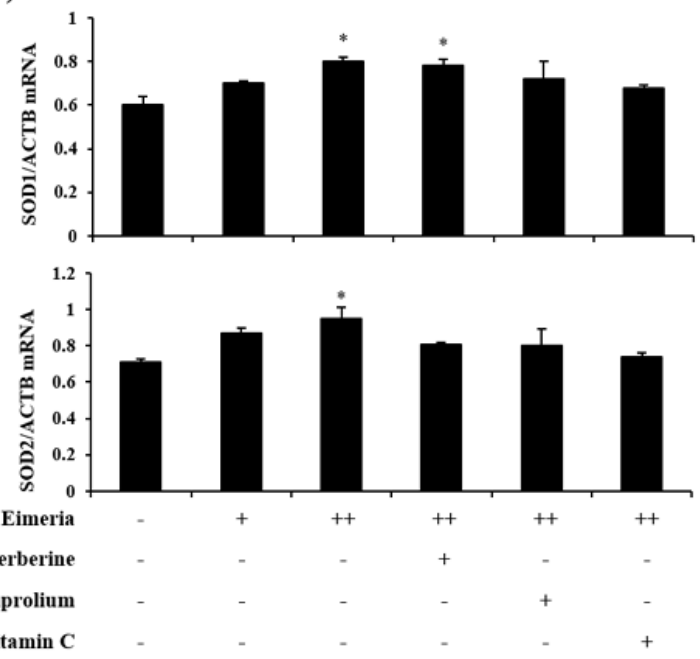

[Gene expression changes of SOD related genes, SOD1 and SOD2 were measured. (A) Reverse transcriptionpolymerase chain reaction analyses of SOD1 and SOD2 expression. (B) Data (mean values of triplicate determinations with upper $95 \%$ confidence intervals) are representative of at least two independent experiments. Asterisks (*) indicate statistically significant differences between infected/treated groups (group 1-5) and the negative control (group 0) $(\mathrm{P}<0.05)]$

Fig. 5. Effect of berberine on SOD related gene expression in chickens

ammoniaporin or VC. It is suggested that berberine did not increase SOD activity by increasing its mRNA expression.

\section{DISCUSSION}

Berberine is a traditional Chinese medicine and is effective on intestinal diseases. It has been shown to protect the intestinal barrier $(\mathrm{Gu}$ et al., 2011; Li et al., 2015) and is widely used in the treatment of bacterial dysentery and gastroenteritis (Sriwilaijareon et al., 2002). Previous study has proved that berberine significantly relieves cecum lesions, reduces oocyst production in E. tenella infected chickens and alleviates the inflammation reaction (Dkhil et al., 2015; Fang et al., 2016), which is confirmed by our present result. $E$. tenella lives in the cecum of chicks and destroys the intestinal epithelium tissue (Iacob and Duma, 2009). The blood seeps into the intestine, leading to bloody diarrhea (InagakiOhara et al., 2006). Berberine blocks the adherence of various pathogenic microorganisms to epithelial cells and inhibits their growth (Sun et al., 1988; Pei et al., 2019). This may be the reason why berberine can relieve cecum lesions and bloody diarrhoea and reduce oocyst production (Table 3 ). Therefore, berberine plays a protective role against coccidiosis infection in chickens.

Berberine was proved to be resistant to increased ROS and lipid oxidation (De Oliveira et al., 2019). Form our data, the increased level of superoxide radical and MDA in infected chickens indicates that oxidative stress is an 
important aspect of the pathogenicity of coccidiosis (Fig. 2 and 3). Berberine reduced the excess superoxide radical by two-thirds and one-half respectively in the liver and cecum and decreased the excess of MDA to a fifth in the cecum. The effect of berberine was not weaker than VC, which has been shown to protect cells from oxidative stress and reduce inflammation (Han et al., 2018). These data collectively suggested that berberine could provide antioxidative protection against oxidative stress induced by E. tenella. It is obvious that the antioxidation and antilipid peroxidation properties of berberine well explain its therapeutic effect on coccidiosis.

SOD, CAT, GPx and other enzymes form an antioxidant system against oxidation by scavenging ROS. In our current study, it showed that the antioxidation of berberine was closely related to the recovery of inhibited SOD activity (Fig. 4). Pirmoradi et al. (2019) observed the similar results that berberine alleviated the lowered activities of SOD in ischemic rats. However, berberine did not significantly enhance the mRNA expression of SOD (Fig. 5), which indicates that the increase of SOD activity is not due to the change of SOD content.

\section{REFERENCES}

Abbas RZ, Iqbal Z, Akhtar MS and Khan MN, 2006. Anticoccidial screening of Azedarachta Indica (Neem) in broilers. Pharmacol, 3: 365-371

Babitha MP, Prakash HS and Shetty HS, 2002. Puriûcation and partial characterization of manganese superoxide dismutase from downy mildew resistant pearl millet seedlings inoculated with Sclerospora graminicola. Plant Sci, 163: 917-924
$\mathrm{Cu} / \mathrm{Zn}$ SOD and Mn SOD are metal enzymes and their activities could be increased by increasing the concentration of metal ions, which alleviates oxidative stress (Bun et al., 2011). The increase in SOD activity by berberine may be related to the metal levels. It was reported that berberine increases the mRNA level by prolonging the half-life of mRNA (Yuan et al., 2017). Berberine may regulate metal concentrations by promoting the expression of metal-associated genes. The mechanism needs further exploration in the future.

Collectively, these data indicate that berberine treatment of chicks infected with E.tenella could reduce oxidative stress through increasing activities of antioxidant enzymes such as SOD to prevent and control chicken coccidiosis.

\section{ACKNOWLEDGEMENTS}

We are thankful to the Shanghai Veterinary Research Institute (SHVRI), Shanghai, China for providing E. tenella. This work was sponsored by grants from the Development Project of Qinghai Key Laboratory (2017-ZJ-Y10).

Bahadoran S, Hassanpour H, Kheirabadi KP and Shekarchian S, 2014. Effect of clopidol and amprolium/ethopabate on performance and intestinal morphology of chickens with experimental coccidiosis. Kafkas Univ Vet Fak Derg, 20: 571-576

Bun SD, Guo YM, Guo FC, Ji FJ and Cao H, 2011. Influence of organic zinc supplementation on the antioxidant status and immune responses of broilers challenged with 
Eimeria tenella. Poult Sci, 90: 1220-1226

Chapman HD, 1997. Biochemical, genetic and applied aspects of drug resistance in Eimeria parasites of the fowl. Avian Pathol, 26: 221-244

De Oliveira JS, Abdalla FH, Dornelles GL, Palma TV, Signor C et al., 2019. Neuroprotective effects of berberine on recognition memory impairment, oxidative stress, and damage to the purinergic system in rats submitted to intracerebroventricular injection of streptozotocin. Psychopharmacology, 236: 641-655

Dhindsa RS, Plumb-Dhindsa $\mathrm{P}$ and Thorpe TA, 1981. Leaf senescence: correlated with increased levels of membrane permeability and lipid peroxidation, and decreased levels of superoxide dismutase and catalase. J Exp Bot, 32: 93-101

Dkhil MA, Metwaly MS, Al-Quraishy S, Sherif NE, Delic D et al., 2015. Anti-Eimeria activity of berberine and identification of associated gene expression changes in the mouse jejunum infected with Eimeria papillate. Parasitol Res, 114: 1581-1593

Fang ZJ, Liu WW, Shi P, Zhang YS and Huang ZW, 2016. Protective effect of berberine on the intestinal cecum in chicks with Eimeria tenella. Avain Biol Res, 9: 235239

Fei CZ, Fan C, Zhao QP, Lin Y, Wang XY et al., 2013. Anticoccidial effects of a novel triazine nitromezuril in broiler chickens. Vet Parasitol, 198: 39-44
Gu LL, Li N, Gong JF, Li QR, Zhu WM et al., 2011. Berberine ameliorates intestinal epithelial tight-junction damage and down-regulates myosin light chain kinase pathways in a mouse model of endotoxinemia. J Infect Dis, 203: 16021612

Guo AJ, Cai JP, Gong W, Yan HB, Luo XN et al., 2013. Transcriptome analysis in chicken cecal epithelia upon infection by Eimeria tenella in vivo. Plos One, 8: e64236

Halliwell B and Chirico S, 1993. Lipid peroxidation: its mechanism, measurement and significance. Am J Clin Nutr, 57: 715725

Han QQ, Shen TT, Wang F, Wu PP and Chen JG, 2018. Preventive and therapeutic potential of vitamin $\mathrm{C}$ in mental disorders. Curr Med Sci, 38: 1-10

Harrison FE, 2012. A critical review of vitamin C for the prevention of age-related cognitive decline and Alzheimer's disease. J Alzheimers Dis, 29: 711-726

Haug A, Williams RB and Larsen S, 2006. Counting coccidial oocysts in chicken faeces: a comparative study of a standard McMaster technique and a new rapid method. Vet Parasitol, 136: 233-242

Iacob O and Duma V, 2009. Clinical, paraclinical and morphopathological aspects in cecaleimeriosis of broilers. Revista Scientia Parasitologica, 10: 43-50

Inagaki-Ohara K, Dewi FN, Hisaeda H, Smith AL, Jimi F et al., 2006. Intestinal intraepithelial 
lymphocytes sustain the epithelial barrier function against Eimeria vermiformis infection. Infect Immun, 74: 5292-5301

Johnson J and Reid WM, 1970. Anticoccidial drugs: lesion scoring techniquesin battery and floor-pan experiments with chickens. Exp Parasitol, 28: 30-36

Liu YK, Hong HX, Lu X, Wang W, Liu F et al., 2017. L-ascorbic acid protected against extrinsic and intrinsic apoptosis induced by cobalt nanoparticles through ROS attenuation. Biol Trace Elem Res, 175: 428-439

Li GX, Wang XM, Jiang T, Gong JF, Niu LY et al., 2015. Berberine prevents intestinal mucosal barrier damage during early phase of sepsis in rat through the Toll-like receptors signaling pathway. Korean J Physiol Pha, 19: 1-7

Long PL, Millard BJ, Joyner LP and Norton CC, 1976. A guide to laboratory techniques used in the study and diagnosis of avian coccidiosis. Folia Vet Lat, 6: 201-217

Masood S, Abbas RZ, Iqbal Z, Mansoor MK, Sindhu ZUD et al., 2013. Role of natural antioxidants for the control of coccidiosis in poultry. Pak Vet J, 33: 401-407

McManus EC, Campbell WC and Cuckler AC, 1968. Development of resistance to quinoline coccidiostats under field and laboratory conditions. J Parasitol, 54: 1190-1193

Pei QH, Li Y, Ge XZ and Tian PE, 2019. Multipath effects of berberine on peach Brown rot fungus Monilinia fructicola. Crop Prot, 116: $92-100$

Pirmoradi Z, Yadegari M, Moradi A, Khojasteh F and Mehrjerdi FZ, 2019. Effect of berberine chloride on caspase- 3 dependent apoptosis and antioxidant capacity in the hippocampus of the chronic cerebral hypoperfusion rat model. Iran J Basic Med Sci, 22: 154-159

Radi AAR and Matkovics B, 1988. Effects of metal ions on the antioxidant enzyme activities, protein contents and lipid peroxidation of carp tissues. Comp Biochem Physiol, 90: 69-72

Sriwilaijareon N, Petmitr S, Mutirangura A, Pinglikitmongkol M and Wilairat P, 2002. Stage specificity of Plasmodium falciparum telomerase and its inhibition by berberine. Parasitol Int, 51: 99-103

Sun D, Courtney HS and Beachey EH, 1988. Berberine sulphate blocks adherence of Streptococcus pyrogenes to epithelial cells, fibronectin and hexadecane. Antimicrob Agents Ch, 32: 1370-1374

Tajick MA and Shohreh B, 2006. Detection of antibiotics residue in chicken meat using TLC. Int J Poult Sci, 5: 611-612

Vervelde L, Vermeulen AN and Jeurissen SHM, 1993. Common epitopes on Eimeria tenella sporozoites and cecal epithelium of chickens. Infect Immun, 61: 4504-4506

Wang SW, Xie BT, Yin LN, Duan LS, Li AH et al., 2010. Increased UV-B radiation affects the viability, reactive oxygen 
species accumulation and antioxidant enzyme activities in maize (Zea mays L.) pollen. Photochem Photobiol, 86: 110-116

Wang YB, Feng HY, Qu Y, Cheng JQ, Zhao ZG et al., 2006. The relationship between reactive oxygen species and nitric oxide in ultraviolet-B-induced ethylene production in leaves of maize seedlings. Environ Exp Bot, 57: 51-61

Yuan ZY, Lu X, Lei F, Hu J, Wang YG et al., 2017. Berberine inhibits mRNA degradation by promoting the interaction between the poly A tail and its binding protein PABP. J Chin Pharm Sci, 26: 53-62 